\title{
T2b Stage Finding
}

National Cancer Institute

\section{Source}

National Cancer Institute. T2b Stage Finding. NCI Thesaurus. Code C48726.

A general term that refers to a TNM finding of a primary tumor growth beyond the level of in situ cancer, minimal subepithelial invasion, or minimal greatest diameter. The definition of T2b TNM finding depends on the specific type of cancer that it refers to; for example, for kidney cancer it refers to a primary tumor that measures more than $10 \mathrm{~cm}$ in greatest dimension, and is limited to the kidney; for bladder cancer it refers to a primary tumor that invades the deep muscularis propria (outer half); for cervical cancer it refers to a primary tumor that invades beyond the uterus but not to the pelvic wall or to the lower third of vagina and there is parametrial invasion. 